\title{
Chronological changes of incidence and prognosis of children with asymptomatic congenital cytomegalovirus infection in Sapporo,
} Japan

\author{
Kei Numazaki* and Tomoko Fujikawa
}

Address: Department of Pediatrics, Sapporo Medical University School of Medicine Sapporo, 060-8543, Japan

Email: Kei Numazaki* - numazaki@sapmed.ac.jp; Tomoko Fujikawa - tomoko@sapmed.ac.jp

* Corresponding author

Published: 06 July 2004

BMC Infectious Diseases 2004, 4:22 doi:10.1 186/147/-2334-4-22

This article is available from: http://www.biomedcentral.com/l47/-2334/4/22

(C) 2004 Numazaki and Fujikawa; licensee BioMed Central Ltd. This is an Open Access article: verbatim copying and redistribution of this article are permitted in all media for any purpose, provided this notice is preserved along with the article's original URL.

\begin{abstract}
Background: Chronological changes of the incidence of congenital cytomegalovirus (CMV) infection and the longitudinal prognosis in children with asymptomatic congenital infection were investigated.

Methods: Congenital CMV infection, as demonstrated by isolation of the virus within the first week of life, was diagnosed in infants born in Sapporo, Japan, during the 26-year period between 1977 and 2002.

Results: Congenital infection was diagnosed in $37(0.31 \%)$ of II,938 infants. Thirty-two infants were $(86.5 \%)$ asymptomatic and $5(13.5 \%)$ were symptomatic at birth.

Conclusions: Although a decrease in the total incidence of congenital CMV infection has been seen in recent years, screening of congenital infection at birth seems to be necessary to detect lateonset neurodevelopmental sequelae.
\end{abstract}

\section{Background}

Human cytomegalovirus (CMV) is the most common cause of congenital and perinatal infections throughout the world. The prevalence of congenital CMV infection varies widely between different populations $(0.2-3.0 \%)$. [1] Less than $5 \%$ of the infants with congenital CMV infection have typical symptoms of cytomegalic inclusion disease (CID), another 5\% have atypical symptoms of CID, and the remainder $(90 \%)$ are asymptomatic at the time of delivery. Factors that have been associated with a poor neurodevelopmental prognosis include the presence of microcephaly, chorioretinitis, intracranial calcification, hydrocephalus or neurologic abnormalities at birth. [2-4]
A decrease in the prevalence of serum antibodies against $\mathrm{CMV}$ has been documented in recent years in consequence to improvement in the social and economic conditions in Japan especially in the last 20 years. [5-7] We have studied the incidence of congenital CMV infection in Japan as reported previously. $[8,9]$

Although asymptomatic at birth, 5 to $17 \%$ of infants with these asymptomatic congenital CMV infections will develop progressive sensorineural hearing loss (SNHL) or other neurodevelopmental difficulties within first 4 years of life. $[10,11]$ Follow-up studies in children with asymptomatic congenital CMV infection have shown that SNHL 
is the most common consequence of this infection. However, prediction of which infants will have developmental disabilities remains controversial. Immunological factors may be associated with the pathogenesis of neurological sequelae. It is possible that progression of neurologic complications is related to the persistent viral infection and replication of CMV or host immunological response to infection.

We studied chronological changes of the incidence of congenital CMV infection during 26 years in Japan and the longitudinal prognosis in children with asymptomatic congenital infection according to growth, cognitive function and the presence and progression of SNHL.

\section{Methods \\ Patients}

Two hospitals (one is Sapporo Medical University Hospital and another one is an affiliated hospital) within the city of Sapporo, Japan were selected for the study. There were no differences between the infants screened and not screened. This paper included the infants previously reported. [8] In a prospective study newborns were screened for the presence of $\mathrm{CMV}$ in urine. Congenital $\mathrm{CMV}$ infection, as demonstrated by isolation of the virus within the first week of life, was diagnosed with a successful virus isolation test in infants born in the city of Sapporo during the 26-year period from January 1977 through December 2002.

The authors evaluated the symptomatic and asymptomatic infants according to the medical records. Reports of symptomatic infants were systematically reviewed to confirm symptomatic status. Children were determined to have symptomatic congenital CMV infection if they had any of the following signs or symptoms during the newborn period: significant intrauterine growth retardation; microcephaly; chorioretinitis; petechiae; hepatosplenomegaly; intracranial calcification; hydrocephalus; severe liver dysfunction or direct hyperbilirubinemia. Neonates with none of these findings were considered to have an asymptomatic congenital CMV infection. Symptomatic and asymptomatic CMV-infected infants were followed up clinically at least for 7 years. Audiologic, neurodevelopmental and psychointellectual assessments, serological study and urine cultures for CMV were performed. Repeat audiologic tests were completed at certain age intervals to evaluate hearing function. We used the definition reported in previous reports to define hearing loss in the children with congenital CMV infection. [10] We detected hearing loss stability through repeated testing.

\section{Auditory brainstem response test}

The hearing loss was assessed using the standard auditory

\section{Serological tests}

Anti-HCMV IgG and IgM were determined using commercially available enzyme-linked immunosorbent assay (ELISA) kit (Medac Diagnostika, Hamburg, Germany).

\section{Isolation of CMV from clinical specimens}

CMV from urinary specimens was isolated according to the standard tissue culture technique using MRC-5 cells. The presence of CMV was confirmed by observation of its characteristic cytopathic effect (CPE) and by immunofluorescent staining with monoclonal antibodies against human CMV (HCMV) immediate early (IE) and early (E) antigens. [12]

\section{Detection of intracellular cytokines-positive CD4+ T cells in specific response to $\mathrm{CMV}$ antigen}

We designed in match control cases in the study. Samples of whole blood were obtained from 6 children with asymptomatic congenital CMV infection (1 month, 2 months, 3 months, 1 year and 2 months, 2 years and 4 months, 5 years and 3 months of age; 4 female and 2 male) and from 6 healthy children of 1 to 5-years of age with serum anti-CMV IgG antibody without serum antiCMV IgM antibody and no viral excretion in to urine (considered as latent condition of postnatal CMV infections). All 6 children with asymptomatic congenital CMV infection excrete the virus into urine at the time of examination. Intracellular cytokines (ICC)-, interferon (IFN)- $\gamma$ and tumor necrosis factor (TNF)- $\alpha-$, positive CD $4^{+} \mathrm{T}$ cells in specific response to CMV antigen were detected according to the methods reported previously. [13-15]

\section{Growth pattern}

Head circumference, height and weight at 3 years or older were assessed using $\mathrm{Z}$ scores according to age and gender for height, weight, weight for height and head circumference.

\section{Neurodevelopmental and intellectual assessments}

Age-appropriate intellectual testing was performed at each scheduled visit. For the purpose of this study results of testing done at 6 years of age using the Wechsler Intelligence Scale for Children (WISC-III) were used for evaluation. For purposes of this study, the IQ/developmental quotient obtained at the latest evaluation was used. Outcome variables were normal intelligence (IQ/DQ $>=90$ ), mental retardation $(\mathrm{IQ} / \mathrm{DQ}<70)$, severe mental retardation $(\mathrm{IQ} / \mathrm{DQ}<50)$, and the presence of major motor deficits. A major motor deficit was defined as the presence of motor abnormalities, such as hypertonia and spasticity that impaired the ability of the patient to perform tasks of daily living.

brainstem response (ABR) test. Children were tested in a quiet room or in a soundproof and faradized booth while 
Table I: Incidence of congenital CMV infection by era in Sapporo, Japan

\begin{tabular}{lccc}
\hline Era & No. of neonates screened & $\begin{array}{c}\text { No. of congenital CMV } \\
\text { infection (\%) }\end{array}$ & $\begin{array}{c}\text { No. of symptomatic congenital CMV } \\
\text { infection (\%) }\end{array}$ \\
\hline $1977-1981$ & 3,084 & $14(0.45 \%)$ & $1(0.032 \%)$ \\
$1982-1985$ & 2,814 & $10(0.36 \%)$ & $1(0.036 \%)$ \\
$1986-1990$ & 2,097 & $7(0.33 \%)$ & $1(0.048 \%)$ \\
$1991-1996$ & 1,898 & $3(0.16 \%)$ & $1(0.053 \%)$ \\
$1997-2002$ & 2,045 & $3(0.15 \%)$ & $1(0.049 \%)$ \\
$1977-2002$ & 11,938 & $37(0.31 \%)$ & $5(0.042 \%)$ \\
\hline
\end{tabular}

sleeping. Surface electrodes were attached in $\mathrm{Cz}$ (active), in $\mathrm{Fz}$ (ground) and at the ear lobes as reference with a twochannel montage. The stimuli were rarefaction clicks delivered monaurally through TDH 39 earphones at a repetition rate of $11.1 / \mathrm{s}$ with $10-\mathrm{dB}$ step increases in intensity until the wave $\mathrm{V}$ became indistinguishable from the baseline. Responses to 2000 clicks were averaged. For each recording condition trials were conducted at least in duplicate.

\section{Results}

Congenital CMV infection was diagnosed in $37(0.31 \%)$ of 11,938 infants born between 1977 and 2002. In the CMV follow-up study $32(86.5 \%)$ were diagnosed as asymptomatic and $5(13.5 \%)$ as symptomatic congenital CMV infection (Table 1). There were $20(54.1 \%)$ male subjects and $17(45.9 \%)$ were female. The duration of urine secretion between symptomatic and asymptomatic congenital CMV infection was $24 \pm 3.2$ and $28 \pm 5.6$ months respectively. The shortest duration of urinary excretion of CMV was 6 months, and the longest duration was 6.5 years. Recurrence of viral excretion after a negative culture was not documented. A decrease in the total incidence of congenital CMV infection has been seen in these 26 years of the study especially in recent years. However, the incidences of symptomatic congenital CMV infection have been slightly increased.

From this basic CMV-infected population identified in the present study, children with no symptoms at birth but who developed other neurologic disturbances (i.e., manifesting clinical evidence of hypotonia, spasticity, hemiparesis, delayed motor development, seizures during the first years of life) or showed seroconversion of antibodies against CMV after birth were not identified. Out of 32 asymptomatic CMV-infected infants, 21 were followed up clinically at least for 7 years. Of the 21 children evaluated with asymptomatic CMV infection, $18(85.7 \%)$ had an IQ/DQ of $>=90,3$ (14.3\%) had an IQ/DQ of 70 to 89 , and none had a major motor disorder on follow-up. Children whose IQ were between 70-89 were categorized as borderline at later examinations. Although all 21 children
Table 2: Characteristics of 21 children with asymptomatic Congenital CMV infection

\begin{tabular}{ll}
\hline Clinical Characteristics & $\begin{array}{l}\text { No. of Positive / No. of } \\
\text { Tested }\end{array}$ \\
\hline Growth Retardation & $1 / 21$ \\
Height less than -2 SD & $1 / 21$ \\
Weight less than -2 SD & $0 / 21$ \\
Mental Retardation & $18 / 21$ \\
IQ/DQ & $3 / 21$ \\
$>=90$ & $2 / 17$ \\
70 to 89 & $1 / 17$ \\
Sensorineural Hearing Loss & $1 / 17$ \\
Unilateral (moderate, 46-70 dB) & \\
Bilateral (mild, 2I-45 dB) & \\
\hline
\end{tabular}

with normal findings on head CT or MRI had a good prognosis, one had growth retardation. Hearing evaluations were also performed during follow-up of 17 children, and 2 had late-onset SNHL (mild bilateral and moderate unilateral) detected after the first years of life. In the children with SNHL hearing loss was diagnosed at the ages of 2 and 3. When children with SNHL detected were compared with the children with normal hearing, no significant differences in cognitive and motor functions were noted (Table 2).

The frequencies of IFN- $\gamma$ and TNF- $\alpha$-positive CD4+ cells among 6 children with asymptomatic congenital CMV infection were investigated. The frequencies were 0.024 to $1.833(0.567 \pm 0.244 \mathrm{SD}) \%$ for IFN- $\gamma$ and 0.043 to 1.974 $(0.523 \pm 0.236 \mathrm{SD}) \%$ for TNF- $\alpha$. The frequencies of IFN- $\gamma$ and TNF- $\alpha$-positive CD4+ cells among 6 healthy children of 1 to 5 -years of age with serum anti-CMV IgG antibody without serum anti-CMV IgM antibody and no viral excretion in to urine (healthy controls) were 0.000 to 0.200 $(0.090 \pm 0.051 \mathrm{SD}) \%$ for IFN $-\gamma$ and 0.000 to $0.140(0.048$ $\pm 0.025 \mathrm{SD}) \%$ for TNF- $\alpha$. Frequencies of CMV-specific $\mathrm{CD} 4{ }^{+} \mathrm{T}$ cells detected by intracellular cytokine staining, both IFN- $\gamma$ and TNF- $\alpha$, were significantly higher in 6 children with asymptomatic congenital infection than those in 6 healthy children of 1 to 5 -years of age with serum 
anti-CMV IgG antibody without serum anti-CMV IgM antibody and no viral excretion in to urine $(\mathrm{p}<0.01)$.

\section{Discussion}

Primary infection of CMV during pregnancy was associated with an increased risk of developmental or intellectual deficit in the offspring. Although $\mathrm{CMV}$ can be transmitted to the fetus even if there is preconceptional maternal immunity, reinfection or reactivated latent infection might be an important determinant of developmental and intellectual impairment in the offspring. The population of seropositive women of childbearing age in low socioeconomic community is about $85 \%$ and about $55 \%$ in populations of high socioeconomic status. [1]

In certain countries parental interest groups have called for screening programs for the general obstetric population in an attempt to reduce the rate of fetal damage with congenital CMV infection. Since annual live births in Japan used to be approximately 1.22 million, four to five thousand infants with congenital CMV infection were presumed to be born each year. Congenital CMV infection is an unsolved public health problem, unlikely to be solved by means other than immune prophylaxis.

Prior studies have shown prolonged viral excretion with congenital CMV infection, and speculated persistent viral replication was a possible explanation for the development of sequelae. Furthermore recent reports have documented the hearing and vision loss may be progressive or late onset. Although progressive hearing loss in children with asymptomatic congenital CMV infection has been described before, less is known about fluctuating hearing loss after asymptomatic congenital CMV infection. [16]

Congenital CMV infection can be definitively diagnosed only in the newborn period, so many of these infections remain undetected. Of the children with asymptomatic congenital CMV infection, only a few infants had an auditory screen based on recognition of congenital CMV infection as the risk factor. All the other neonates with asymptomatic congenital CMV infection who had auditory screening were tested because of risk criteria other than CMV infection. Although we did not detect very severe neurological sequelae in children with asymptomatic congenital infection compared to the previous reports, all children with congenital CMV infection should be screened for hearing loss. [10,11]

The frequencies CMV-specific CD4+T cells were correlated with the condition of viral infections such as primary infection or reactivation and positive for other virological makers, and reflect the change of adoptive immunity against CMV. $[14,15]$ The ICC staining to detect CMV-specific CD4+ T cells were also available for the evaluation of immunological conditions in children with symptomatic congenital CMV infection. [17] From the results of present study a high frequency of CMV-specific CD4+ T cells may indicate the presence of stimulation against cellular immunity related to asymptomatic congenital CMV infection. The ICC staining assay can be useful as a tool for realtime monitoring of CMV-specific cellular immunity in congenitally infected children. These findings should assist pediatricians, neonatologists, neurologists, developmentalists, and infectious disease specialists in counseling families to assess the condition of children with congenital CMV infection.

Despite the lack of information on possible sequelae in approximately one third of the children with congenital CMV infection, our findings indicate 2 of 17 (11.8\%) infants with asymptomatic congenital CMV infection had late-onset SNHL. Delayed-onset SNHL followed congenital CMV infection would not have been identified by universal screening of newborns for hearing. Infants with symptomatic disorders at birth are more likely to be identified and have appropriate virological testing for congenital CMV infection in the newborn period. These infants will likely have a hearing evaluation completed at the time of diagnosis. However, infants with asymptomatic infection may not be recognized as being at increased risk for late-onset neurodevelopmental disorders.

In summary the total incidence of congenital CMV infection in 11,938 children in Sapporo, Japan was $0.31 \%$, between 1977 and 2002. Although a decrease in the total incidence of congenital CMV infection has been seen in recent years, the incidences of symptomatic congenital have been slightly increased. As a decrease in the prevalence of serum antibodies against CMV has been documented in recent years, the incidence of symptomatic congenital infection may be related to that of primary CMV infection during pregnancy. Congenital CMV infection as the probable leading infectious cause of SNHL in childhood. Each year more children will continue to have late-onset neurodevelopmental disorders caused by congenital CMV infection. Entirely new approaches to prevention and treatment of congenital CMV infection are necessary, including antiviral interventions and the development of a vaccine strategy.

\section{Acknowledgements}

This work was supported by research grants from the Ministry of Education, Science and Culture of Japan.

\section{References}

I. Numazaki K, Chiba S: Current aspects of diagnosis and treatment of cytomegalovirus infections in infants. Clin Diagn Virol 1997, 8:169-I8I.

2. Conboy TJ, Pass RF, Stagno S, Alford CA, Myers GJ, Britt WJ, McCollister FP, Summers MN, McFarland CE, Boll TJ: Early clinical manifestations and intellectual outcome in children with 
symptomatic congenital cytomegalovirus infection. $\int$ Pediatr | 987, I I I:343-348.

3. Boppana SB, Fowler KB, Vaid Y, Hedlund G, Stagno S, Britt W], Pass RF: Neuroradiographic findings in the newborn period and long-term outcome in children with symptomatic congenital cytomegalovirus infection. Pediatrics 1997, 99:409-4|4.

4. Ivarsson S-A, Lernmark B, Svanberg L: Ten-year clinical, developmental, and intellectual follow-up of children with congenital cytomegalovirus infection without neurologic symptoms at one year of age. Pediatrics 1997, 99:800-803.

5. Hirota K, Muraguchi K, Watanabe N, Okumura M, Kozu M, Takahashi K, Machida Y, Funayama Y, Oshima T, Numazaki Y: Prospective study on maternal, intrauterine, and perinatal infections with cytomegalovirus in Japan during 1976-1990. J Med Virol 1992, 37:303-306.

6. Nishimura $\mathrm{N}$, Kimura $\mathrm{H}$, Yabuta $\mathrm{Y}$, Tanaka $\mathrm{N}$, Ito $\mathrm{Y}$, Ishikawa $\mathrm{K}$, Suzuki C, Morishima T: Prevalence of maternal cytomegalovirus (CMV) antibody and detection of CMV DNA in amniotic fluid. Microbiol Immunol 1999, 43:78I-784.

7. Numazaki K, Fujikawa T: Prevalence of serum antibodies to cytomegalovirus in pregnant women in Sapporo, Japan. Int J Infect Dis 2002, 6: I 147- I48.

8. Numazaki K, Chiba S: PCR detection of cytomegalovirus DNA in serum as test for congenital cytomegalovirus infection. J Clin Microbiol I 996, 34: I87|-I872.

9. Numazaki K, Fujikawa T, Chiba S: Relationship between seropositivity of husbands and primary cytomegalovirus infection during pregnancy. I Infect Chemother 2000, 6:104-106.

10. Barbi M, Binda S, Caroppo S, Ambrosetti U, Corbetta C, Sergi P: A wider role for congenital cytomegalovirus infection in sensorineural hearing loss. Pediatr Infect Dis J 2003, 22:39-42.

II. Fowler KB, McCollister FP, Dahle AJ, Boppana S, Britt WJ, Pass RF: Progressive and fluctuating sensorineural hearing loss in children with asymptomatic congenital cytomegalovirus infection. J Pediatr 1997, 130:624-630.

12. Numazaki K, Nagata N, Chiba S: Evaluation of the shell vial preCPE method using monoclonal antibodies for the detection of human cytomegalovirus infection in the field of pediatrics. In Vivo 1992, 6:513-516.

13. Asanuma H, Sharp M, Maecker HT, Mario VC, Arvin AM: Frequencies of memory $T$ cells specific for varicella-zoster virus, herpes simplex virus, and cytomegalovirus by intercellular detection of cytokine expression. J Infect Dis 2000, 18 1:859-866.

14. Fujikawa T, Numazaki K, Asanuma $\mathrm{H}$, Tsutsumi H: Human cytomegalovirus infection during pregnancy and detection of specific $\mathbf{T}$ cells by intracellular cytokine staining. Int $J$ Infect Dis 2003, 7:215-221.

15. Fujikawa T, Numazaki K, Asanuma H, Kudo R, Tsutsumi H: Frequency of human cytomegalovirus-specific $T$ cells during pregnancy determined by intracellular cytokine staining. J Med Virol 2003, 7I:527-53I.

16. Bale JF Jr, Blackman JA, Sato Y: Outcome in children with symptomatic congenital cytomegalovirus infection. I Child Neurol 1990, 5:131-136.

17. Numazaki K, Fujikawa T, Asanuma H: Immunological evaluation and clinical aspects of children with congenital cytomegalovirus infection. Congenital Anomalies 2002, 42:181-186.

\section{Pre-publication history}

The pre-publication history for this paper can be accessed here:

$$
\text { http://www.biomedcentral.com/1471-2334/4/22/prepub }
$$

\begin{tabular}{|l|}
\hline Publish with Biomed Central and every \\
scientist can read your work free of charge \\
"BioMed Central will be the most significant development for \\
disseminating the results of biomedical research in our lifetime. " \\
Sir Paul Nurse, Cancer Research UK \\
Your research papers will be: \\
• available free of charge to the entire biomedical community \\
• peer reviewed and published immediately upon acceptance \\
• cited in PubMed and archived on PubMed Central \\
• yours - you keep the copyright \\
Submit your manuscript here: \\
http://www.biomedcentral.com/info/publishing_adv.asp
\end{tabular}

